\title{
PRODUÇÃO DE ALFACE NO SISTEMA ORGÂNICO EM SUCESSÃO A AVEIA PRETA, SOBRE A PALHA, E DIFERENTES COBERTURAS DO SOLO
}

\author{
ORGANIC LETTUCE PRODUCTION OVER BLACK OAT TILLAGE, AND \\ DIFFERENT SOIL COVERING
}

\author{
Átila Francisco MÓGOR ${ }^{1}$ \\ Francisco Luiz Araújo CÂMARA²
}

\begin{abstract}
RESUMO
Objetivou-se avaliar o efeito da cobertura do solo com aveia preta e manutenção da palha sobre o terreno, bem como cobertura do solo com filme de polietileno preto, sobre o desenvolvimento, produção e teor de nitrogênio de alface cultivada no sistema orgânico. Definiram-se cinco manejos da cobertura do solo: sem cobertura, coberto com filme de polietileno preto, coberto com aveia deitada, coberto com aveia ceifada e coberto com aveia na sua forma natural, para o cultivo de três cultivares de alface. $O$ experimento foi conduzido na Associação Brasileira de Agricultura Biodinâmica (ABD), Botucatu - SP, em delineamento experimental de blocos ao acaso, com quatro repetições, em análise estatística com parcelas subdivididas. Concluiu-se que, as coberturas do solo promoveram melhor desenvolvimento e maior produção de alface quando comparadas ao solo sem cobertura. Entre os manejos da cobertura do solo, o solo coberto com plástico preto promoveu a maior produção de alface, e entre os manejos da palha, a alface lisa apresentou maior produção no solo coberto com aveia deitada, a crespa nos solos cobertos com aveia deitada e aveia em pé, e a americana nos solos cobertos com aveia ceifada e aveia em pé.
\end{abstract}

Palavras-chave: Produção orgânica; Lactuca sativa L.; cobertura do solo; Avena strigosa.

\begin{abstract}
The goal of this research was to evaluate the effect of the soil covering with black oats straw, and soil covered with black plastic, in growth, production and nitrogen content of the lettuce in organic production system. There have been defined five handling systems for soil covering: without cover, covered with black plastic, covered with laying oats, covered with harvested oats, and covered with oats straw in natural form, for growing three cultivars of lettuce. The trial was conducted on the Brazilian Association of Biodynamic Agriculture (ABD), Botucatu - SP. It was used the randomized blocks design in split plot system, with four replications. It has been concluded, that all soil covering systems raised better lettuce production them uncovered soil. Soil covered with black plastic raised better lettuce production among the soil covering systems. In tilled soils, the butter head lettuce showed better production over soil covered with laying oats, the green leaf lettuce shoed better production over soil covered with laying oats, and covered with oats straw in natural form, and the iceberg lettuce showed better production over soil covered with harvested oats and covered with oats straw in natural form.

Key-words: Organic production; Lactuca sativa L.; tillage; Avena strigosa.
\end{abstract}

${ }^{1}$ Engenheiro Agrônomo, Doutor em Agronomia área de concentração em Horticultura, Professor do Departamento de Fitotecnia e Fitossanitarismo
da UFPR, Rua dos Funcionários, 1540, 80035-050, Curitiba - PR. E-mail: atila.mogor@ufpr.br. Autor para correspondência.
${ }^{2}$ Engenheiro Agrônomo, Doutor em Agronomia, Professor do Departamento de Produção Vegetal - Setor de Horticultura da UNESP-FCA, Fazenda
Experimental Lageado. Rua José Barbosa de Barros, 1780, Caixa Postal 237, 18610-307, Botucatu, SP. E-mail: chicocamara@fca.unesp.br. 


\section{INTRODUÇÃO}

A alface (Lactuca sativa L.) é uma hortaliça tradicionalmente cultivada por pequenos produtores. Pelas características fundiárias dos pólos de produção aliada à alta demanda de mão-de-obra ( $22 \%$ do custo de produção) em seu cultivo (FNP CONSULTORIA E AGROINFORMATIVOS, 2003) torna-se importante no contexto da sustentabilidade do agricultor familiar.

Dentre as muitas tecnologias utilizadas no cultivo da alface, diversos autores citam as vantagens da cobertura do solo por manter a umidade, melhorar sua aeração, reduzir as perdas por lixiviação e erosão (MÜLLER,1991; SADE, 1998; CARDOSO, 1998; PEREIRA et al., 2000; BORKERT et al., 2003). Essa cobertura pode ser feita com material de origem vegetal, como palhadas diversas ou com filmes plásticos, normalmente de coloração preta (VERDIAL et al., 2000).

O conceito orgânico de produção tem entre seus fundamentos, a reciclagem e a utilização de insumos naturais, buscando a auto-suficiência da propriedade (INSTITUTO BIODINÂMICO, 2004). Diante disso, o cultivo de alface em sucessão à produção de material vegetal com a finalidade de cobertura do solo deve ser considerada.

Neste trabalho, objetivou-se avaliar o desenvolvimento, a produção e o teor foliar de nitrogênio em alface dos tipos americana, lisa e crespa, cultivadas sobre a palha em sucessão a aveia preta (Avena strigosa), bem como em solo coberto com plástico preto e solo sem cobertura, no sistema orgânico de produção.

\section{METODOLOGIA}

O experimento foi conduzido na área experimental da Associação Brasileira de Agricultura Biodinâmica (ABD) localizada no bairro Demétria, município de Botucatu, São Paulo, sob as coordenadas geofísicas aproximadas de $22^{\circ} 54^{\prime} \mathrm{S}$; $48^{\circ} 27^{\prime}$ W e altitude de $850 \mathrm{~m}$, em clima do tipo Cwa, segundo a classificação de Köppen, e solo de textura média, fase arenosa, classificado como Latossolo Vermelho Amarelo (BERTALOT, 2002).

Para o cultivo de três cultivares de alface: Elisa, Verônica e Lucy Brown, dos tipos lisa, crespa e americana, respectivamente. Utilizaram-se cinco manejos da cobertura do solo: sem cobertura; cobertura com plástico de cor preta; cobertura com aveia preta cultivada sobre o canteiro e acamada antes do transplante das mudas de alface; cobertura com aveia preta cultivada sobre o canteiro e ceifada antes do transplante das mudas de alface; cobertura com aveia preta cultivada sobre o canteiro e mantida na forma natural, ou seja, em pé.

Nos tratamentos de cobertura com material vegetal a semeadura da aveia preta foi realizada em julho de 2000, dez dias após a fertilização da área experimental e confecção dos canteiros, de modo a completar seu ciclo e estar seca até a época de transplante das mudas de alface. No solo sem cobertura e no solo coberto com plástico preto, procedeu-se a eliminação periódica das plantas invasoras até a colocação do filme plástico e transplante simultâneo das mudas na área experimental, que ocorreu em janeiro de 2001.

As mudas foram produzidas em ambiente protegido (viveiro coberto com filme de polietileno) na área experimental da ABD, utilizando-se bandejas de poliestireno expandido com 288 células preenchidas com substrato composto de $1 / 3$ de casca de arroz carbonizada e 2/3 de composto orgânico, com uma planta por célula. $O$ transplante ocorreu 26 dias após a semeadura, quando o sistema radicular das mudas estava suficientemente desenvolvido, mantendo íntegro o substrato quando da retirada das plantas das bandejas.

A fertilização da área experimental ocorreu com base na analise química do solo, seguindo as diretrizes do INSTITUTO BIODINÂMICO (2000) quanto à utilização dos tipos de fertilizantes. Como fonte de matéria orgânica e potássio utilizaram-se esterco bovino curtido na dose de $60 \mathrm{t} \mathrm{ha}^{-1}$; como fonte de fósforo utilizou-se termofosfato na dose de $1500 \mathrm{~kg} \mathrm{ha}^{-1}$ (TRANI et al., 1996). Todos os fertilizantes foram distribuídos e incorporados manualmente, de forma homogênea em toda a área, dez dias antes da semeadura da aveia preta.

Os cinco diferentes manejos de cobertura do solo foram distribuídos em um delineamento de blocos ao acaso, com quatro repetições em parcelas de $11 \mathrm{~m}^{2}(1,10 \times 10,00 \mathrm{~m})$, divididas em três subparcelas de $3,6 \mathrm{~m}^{2}$, uma para cada cultivar. As unidades experimentais foram compostas de quarenta plantas espaçadas de $0,25 \times 0,33 \mathrm{~m}$, distribuídas em quatro linhas de plantio. A necessidade hídrica das plantas foi suprida pela manutenção da capacidade de campo utilizando-se sistema de irrigação por aspersão. No solo sem cobertura procedeu-se a retirada manual periódica das plantas invasoras. Nas avaliações foram utilizadas as plantas das linhas centrais, com total de 20 plantas úteis.

Procederam-se três coletas de plantas, sendo a primeira doze dias após o transplante (12 DAT), a segunda vinte e quatro dias após o transplante (24 DAT), e a terceira na colheita, que ocorreu 36 dias após o transplante (36 DAT). Na primeira coleta foram retiradas, aleatoriamente, três plantas das linhas centrais de cada unidade experimental; nas duas coletas subseqüentes foram retiradas duas plantas, levando-se em conta que estas não estivessem imediatamente próximas ao espaço deixado pelas retiradas na coleta anterior.

Foram avaliados: altura da planta (correspondendo à distância vertical do colo da planta até a extremidade da folha mais expandida), número de folhas e massa fresca das folhas em cada coleta.

Para avaliar o teor de nitrogênio das plantas em cada coleta, efetuou-se a análise química das folhas, utilizando a metodologia sugerida por MALAVOLTA et al. (1997).

Utilizou-se delineamento experimental de blocos ao acaso, com quatro repetições, em análise estatística no esquema de parcelas subdivididas. As médias foram comparadas pelo teste de Tukey ao nível de $5 \%$ de probabilidade.

Scientia Agraria, Curitiba, v.8, n.3, p.239-245, 2007. 


\section{RESULTADOS E DISCUSSÃO}

Aos 12 dias após o transplante (DAT), avaliando o efeito dos manejos de cobertura do solo sobre o desenvolvimento das três cultivares de alface, verificou-se a menor altura das plantas no solo sem cobertura, quando comparado ao solo coberto com plástico preto para alface americana, solo coberto com aveia ceifada para alface lisa e solo coberto com aveia deitada para alface crespa (Tabela 1 ). Como a alface tem uma taxa de desenvolvimento inicial lenta (LYRA et al., 2003), as plantas pouco diferiram quanto ao número de folhas (Tabela 2). Entretanto, verifica-se o efeito das coberturas do solo no desenvolvimento inicial, ao se comparar a massa fresca das plantas, menor no solo sem cobertura nas três cultivares de alface (Tabela 3 ).

TABELA 1 - Altura (cm) das plantas de alface americana (AA), lisa (AL) e crespa (AC) aos 12, 24 e 36 dias após o transplante (DAT), nos manejos de cobertura do solo: sem cobertura ( $\mathrm{SsC}$ ), coberto com plástico preto (ScPP), coberto com aveia deitada (ScAD), coberto com aveia ceifada (ScAC) e coberto com aveia em pé (ScAP). Botucatu, 2007.

\begin{tabular}{|c|c|c|c|c|c|}
\hline \multirow[b]{2}{*}{ Tipos de alface (Ti) } & \multicolumn{5}{|c|}{ Tratamentos $(\mathrm{T})$} \\
\hline & SsC & ScPP & ScAD & ScAC & ScAP \\
\hline \multicolumn{6}{|l|}{12 DAT } \\
\hline$\overline{\mathrm{AA}}$ & 10,30 a $B$ & 12,02 a $A$ & 11,15 a $A B$ & 10,22 b B & 10,82 a $A B$ \\
\hline $\mathrm{AL}$ & 10,75 a $B$ & 11,17 a $A B$ & 10,77 a $B$ & 12,55 a $A$ & 11,32 a $A B$ \\
\hline $\mathrm{AC}$ & 9,95 a B & 11,20 a $A B$ & 11,75 a $A$ & $10,40 \mathrm{~b} \mathrm{AB}$ & 10,50 a $A B$ \\
\hline \multicolumn{6}{|l|}{$\overline{\mathrm{CV}}(\%)(\mathrm{T}) \quad 9,82$} \\
\hline CV (\%) (Ti) 6,12 & & & & & \\
\hline \multicolumn{6}{|l|}{24 DAT } \\
\hline$\overline{\mathrm{AA}}$ & $12,60 \mathrm{ab} B C$ & $16,12 \mathrm{~b} \mathrm{~A}$ & $13,25 a b$ B & 11,10 a C & 13,50 a B \\
\hline $\mathrm{AL}$ & 13,30 a B & 15,95 b A & 12,85 b B & 11,97 a B & 12,75 a $B$ \\
\hline $\mathrm{AC}$ & 11,70 b CD & 17,67 a A & 14,60 a B & 11,17 a D & 13,15 a BC \\
\hline \multicolumn{6}{|l|}{$\overline{\mathrm{CV}}(\%)(\mathrm{T}) \quad 6,40$} \\
\hline CV (\%) (Ti) 6,01 & & & & & \\
\hline \multicolumn{6}{|l|}{36 DAT } \\
\hline$\overline{\mathrm{AA}}$ & $11,80 \mathrm{~b} \mathrm{C}$ & 17,60 a $A$ & $12,85 \mathrm{c} \mathrm{BC}$ & 13,42 a $B C$ & 13,90 b B \\
\hline $\mathrm{AL}$ & $12,62 a b C$ & 17,47 a $A$ & 14,57 b B & 13,67 a $B C$ & 13,75 b BC \\
\hline$A C$ & 13,57 a C & 17,22 a $A$ & 16,62 a $A B$ & 15,10 a $B C$ & 15,70 a $A B$ \\
\hline
\end{tabular}

CV (\%) (T) 5,66

CV (\%) (Ti) 6,81

Médias seguidas de mesma letra minúscula na coluna, para cada data de avaliação, não diferem entre si pelo teste de Tukey a $5 \%$ de probabilidade.

Médias seguidas da mesma letra maiúscula na linha, não diferem entre si pelo teste de Tukey a $5 \%$ de probabilidade. 
MÓGOR, A.F. e CÂMARA, F.L.A. Produção de alface no sistema...

TABELA 2 - Número de folhas por planta de alface americana (AA), lisa (AL) e crespa (AC) aos 12, 24 e 36 dias após o transplante (DAT), nos manejos de cobertura do solo: sem cobertura (SsC), coberto com plástico preto (ScPP), coberto com aveia deitada (ScAD), coberto com aveia ceifada (ScAC) e coberto com aveia em pé (ScAP). Botucatu, 2007.

\begin{tabular}{|c|c|c|c|c|c|}
\hline \multirow[b]{2}{*}{ Tipos de alface (Ti) } & \multicolumn{5}{|c|}{ Tratamentos $(\mathrm{T})$} \\
\hline & SsC & ScPP & ScAD & ScAC & ScAP \\
\hline \multicolumn{6}{|l|}{12 DAT } \\
\hline $\begin{array}{l}\mathrm{AA} \\
\mathrm{AL} \\
\mathrm{AC}\end{array}$ & $\begin{array}{l}10,47 \text { a } A \\
5,82 \text { b B } \\
5,75 \text { b B }\end{array}$ & $\begin{array}{r}6,85 \text { a } B \\
7,52 \text { a } A \\
6,80 \text { a } A B\end{array}$ & $\begin{array}{l}11,17 \text { a } A \\
6,77 \text { b } A B \\
6,62 \text { b AB }\end{array}$ & $\begin{array}{c}6,82 \text { ab B } \\
6,67 \text { b AB } \\
7,67 \text { a } A\end{array}$ & $\begin{array}{c}5,72 \text { b B } \\
6,32 \text { ab B } \\
7,10 \text { a A }\end{array}$ \\
\hline \multicolumn{6}{|l|}{$\begin{array}{ll}\mathrm{CV}(\%)(\mathrm{T}) & 17,68 \\
\mathrm{CV}(\%)(\mathrm{Ti}) & 22,42 \\
\end{array}$} \\
\hline \multicolumn{6}{|l|}{24 DAT } \\
\hline $\begin{array}{l}\mathrm{AA} \\
\mathrm{AL} \\
\mathrm{AC}\end{array}$ & $\begin{array}{c}15,37 \text { a } A \\
9,67 \text { b BC } \\
8,00 \text { c C }\end{array}$ & $\begin{array}{l}12,50 \text { a } B \\
13,57 \text { a } A \\
13,92 \text { a } A \\
\end{array}$ & $\begin{array}{l}16,32 \text { a } A \\
10,35 \text { b B } \\
10,82 \text { b B }\end{array}$ & $\begin{array}{l}8,60 \text { b C } \\
8,17 \text { b C } \\
10,40 \text { a B }\end{array}$ & $\begin{array}{c}8,32 \text { c C } \\
10,80 \text { b B } \\
12,67 \text { a A }\end{array}$ \\
\hline $\begin{array}{ll}\text { CV (\%) (T) } & 14,65 \\
\text { CV (\%) (Ti) } & 14,49 \\
\end{array}$ & & & & & \\
\hline \multicolumn{6}{|l|}{36 DAT } \\
\hline $\begin{array}{l}\mathrm{AA} \\
\mathrm{AL} \\
\mathrm{AC}\end{array}$ & $\begin{array}{l}19,75 \text { a } A \\
9,30 \text { b } D \\
9,82 \text { b B }\end{array}$ & $\begin{array}{l}17,17 \text { b } \mathrm{B} \\
21,17 \text { a A } \\
17,15 \text { b A }\end{array}$ & $\begin{array}{l}21,00 \text { a A } \\
15,80 \text { b B } \\
15,67 \text { b A }\end{array}$ & $\begin{array}{l}19,97 \text { a } A \\
11,67 \text { c C } \\
15,75 \text { b A }\end{array}$ & $\begin{array}{c}15,50 \text { ab B } \\
14,22 \text { b B } \\
16,92 \text { a A }\end{array}$ \\
\hline
\end{tabular}

CV $(\%)(T) 14,63$

$\mathrm{CV}(\%)(\mathrm{Ti}) 8,20$

Médias seguidas de mesma letra minúscula na coluna, para cada data de avaliação, não diferem entre si pelo teste de Tukey a $5 \%$ de probabilidade.

Médias seguidas da mesma letra maiúscula na linha, não diferem entre si pelo teste de Tukey a $5 \%$ de probabilidade.

TABELA 3 - Massa fresca (g planta-1) das plantas de alface americana (AA), lisa (AL) e crespa (AC) aos 12, 24 e 36 dias após o transplante (DAT), nos manejos de cobertura do solo: sem cobertura (SsC), coberto com plástico preto (ScPP), coberto com aveia deitada (ScAD), coberto com aveia ceifada (ScAC) e coberto com aveia em pé (ScAP). Botucatu, 2007.

\begin{tabular}{|c|c|c|c|c|c|}
\hline \multirow[b]{2}{*}{ Tipos de alface (Ti) } & \multicolumn{5}{|c|}{ Tratamentos $(\mathrm{T})$} \\
\hline & SsC & ScPP & ScAD & ScAC & ScAP \\
\hline \multicolumn{6}{|l|}{12 DAT } \\
\hline$\overline{\mathrm{AA}}$ & 18,40 b D & 46,17 a $A$ & 38,65 a $B$ & 30,72 b C & 32,92 a C \\
\hline $\mathrm{AL}$ & 24,47 a $C$ & 37,70 b AB & 39,42 a $A$ & 34,60 a $B$ & 34,82 a B \\
\hline $\mathrm{AC}$ & $18,70 \mathrm{~b} \mathrm{C}$ & 37,22 b A & 38,00 a $A$ & 29,45 b B & 29,35 b B \\
\hline \multicolumn{6}{|l|}{$\overline{\mathrm{CV}}(\%)(\mathrm{T}) \quad 8,05$} \\
\hline CV (\%) (Ti) 5,83 & & & & & \\
\hline \multicolumn{6}{|l|}{24 DAT } \\
\hline$\overline{\mathrm{AA}}$ & $47,35 \mathrm{~b} \mathrm{C}$ & 218,20 a $A$ & 82,15 b B & 70,50 b B & 72,02 b B \\
\hline $\mathrm{AL}$ & 65,25 a C & 161,95 b A & 149,60 a $A$ & 63,50 b C & 85,95 b B \\
\hline $\mathrm{AC}$ & 56,72 ab D & 205,52 a A & 141,20 a B & 97,20 a C & 105,92 a C \\
\hline \multicolumn{6}{|l|}{$\mathrm{CV}(\%)(\mathrm{T}) \quad 9,11$} \\
\hline \multirow{2}{*}{\multicolumn{6}{|c|}{$\begin{array}{ll}\mathrm{CV}(\%)(\mathrm{II}) & 8,01 \\
36 \mathrm{DAT} & \end{array}$}} \\
\hline & & & & & \\
\hline$\overline{\mathrm{AA}}$ & 52,02 b D & 403,05 a $A$ & 98,97 b C & 128,57 b BC & $148,50 \mathrm{~b} \mathrm{~B}$ \\
\hline $\mathrm{AL}$ & $67,37 \mathrm{ab} D$ & 236,70 b A & 202,70 a $B$ & 81,27 c D & 156,27 b C \\
\hline$A C$ & 91,42 a D & 256,87 b A & 205,27 a B & 174,35 a C & 185,15 a BC \\
\hline
\end{tabular}

CV (\%) (T) 9,39

CV (\%) (Ti) 8,57

Médias seguidas de mesma letra minúscula na coluna, para cada data de avaliação, não diferem entre si pelo teste de Tukey a $5 \%$ de probabilidade.

Médias seguidas da mesma letra maiúscula na linha, não diferem entre si pelo teste de Tukey a $5 \%$ de probabilidade. 
Aos 12 DAT o teor de nitrogênio das plantas não diferiu significativamente entre as cultivares $e$ manejos, variando entre 30,8 a $42,2 \mathrm{~g} \mathrm{~kg}^{-1}$ da massa seca (Tabela 4), próximos aos encontrados por SILVA JR. e SOPRANO (1997) e ALVARENGA et al. (2000), trabalhando em sistema hidropônico e convencional, respectivamente, com teores variando de 20,0 a 50,0 $\mathrm{g} \mathrm{kg}^{-1}$, segundo os autores, adequados ao desenvolvimento normal das plantas de alface.

TABELA 4 - Teor de nitrogênio $\left(\mathrm{g} \mathrm{kg}^{-1}\right)$ das plantas de alface americana (AA), lisa (AL) e crespa (AC) aos 12, 24 e 36 dias após o transplante (DAT), nos manejos de cobertura do solo: sem cobertura (SsC), coberto com plástico preto (ScPP), coberto com aveia deitada (ScAD), coberto com aveia ceifada (ScAC) e coberto com aveia em pé (ScAP). Botucatu, 2007.

\begin{tabular}{|c|c|c|c|c|c|c|}
\hline \multirow[b]{2}{*}{ Tipos de alface (Ti) } & \multicolumn{6}{|c|}{ Tratamentos $(\mathrm{T})$} \\
\hline & SsC & ScPP & ScAD & ScAC & ScAP & $\begin{array}{l}\text { Médias de } \\
(\mathrm{Ti})\end{array}$ \\
\hline \multicolumn{7}{|l|}{12 DAT } \\
\hline AA & 33,8 & 42,2 & 33,2 & 30,8 & 36,0 & $35,2 a$ \\
\hline $\mathrm{AL}$ & 32,9 & 40,1 & 34,3 & 32,6 & 36,2 & 35,2 a \\
\hline$A C$ & 31,2 & 40,6 & 36,5 & 35,6 & 35,5 & $35,9 \mathrm{a}$ \\
\hline Médias de (T) & $32,6 \mathrm{~B}$ & $40,9 \mathrm{~A}$ & $34,6 \mathrm{~B}$ & $33,0 \mathrm{~B}$ & $35,9 \mathrm{~B}$ & \\
\hline \multicolumn{7}{|l|}{$\begin{array}{ll}\text { CV\% (T) } & 7,39 \\
\text { CV\% (Ti) } & 7,03\end{array}$} \\
\hline \multicolumn{7}{|l|}{24 DAT } \\
\hline $\mathrm{AA}$ & 27,3 a B & 33,0 a $A$ & 25,8 a B & 23,2 b B & 23,3 a $B$ & \\
\hline $\mathrm{AL}$ & $24,5 a b A$ & 28,1 b A & 24,8 a $A$ & $26,1 \mathrm{ab} A$ & 24,5 a $A$ & \\
\hline$A C$ & 23,6 b B & $30,1 \mathrm{ab} A$ & 26,1 a $A B$ & 27,7 a $A B$ & 24,4 a B & \\
\hline \multicolumn{7}{|l|}{ 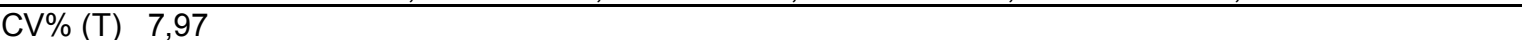 } \\
\hline CV\% (Ti) 7,72 & & & & & & \\
\hline \multicolumn{7}{|l|}{36 DAT } \\
\hline $\mathrm{AA}$ & 24,5 a $A$ & 24,1 a A & 24,5 a $A$ & 20,3 b B & 20,1 a B & \\
\hline $\mathrm{AL}$ & 20,8 b B & 24,6 a $A$ & 23,2 a $A B$ & 23,5 a $A B$ & 22,8 a $A B$ & \\
\hline$A C$ & $23,4 a b$ A & 23,6 a $A$ & 24,0 a A & 23,7 a $A$ & 21,0 a $A$ & \\
\hline
\end{tabular}

CV\% (T) 9,21

CV\% (Ti) 7,34

Médias seguidas de mesma letra minúscula na coluna, para cada data de avaliação, não diferem entre si pelo teste de Tukey a $5 \%$ de probabilidade.

Médias seguidas da mesma letra maiúscula na linha, não diferem entre si pelo teste de Tukey a $5 \%$ de probabilidade.

VERDIAL et al. (2001) verificaram a redução da concentração de $\mathrm{N}$ em plantas de alface cultivadas em solo coberto com bagaço de cana, quando comparado ao solo sem cobertura e coberto com plástico preto, atribuindo esse efeito à fixação do elemento durante o processo de equilíbrio na relação $\mathrm{C} / \mathrm{N}$ da cobertura vegetal. No presente trabalho, os teores aos 12 DAT (Tabela 4) não encontram correspondência na observação daqueles autores ao comparar o solo sem cobertura com os manejos da palha, indicando que o processo de decomposição da palha da aveia preta, não influenciou negativamente a disponibilidade de $\mathrm{N}$ para as plantas de alface no início do ciclo. Entretanto, verifica-se que as plantas cultivadas no solo coberto com plástico preto apresentaram os maiores teores de $\mathrm{N}$ (Tabela 4). Possivelmente, a maior velocidade de nitrificação em solos cobertos com plástico preto, observado por SADE (1998), justifique esse efeito.

Aos 24 DAT, comparando as três cultivares quanto à altura das plantas, verificou-se que a lisa e a crespa diferiram significativamente no solo sem cobertura, com a alface lisa apresentando maior altura, já no solo coberto com aveia deitada e coberto com plástico preto ocorreu o inverso, com a crespa apresentando a maior altura, enquanto nos demais tratamentos a altura das três cultivares não diferiu significativamente (Tabela 1). Entretanto, ao se comparar o efeito dos tratamentos, observou-se que as coberturas do solo influenciaram a expansão das folhas, que ocorreu com maior intensidade no solo coberto com plástico preto, com as três cultivares apresentando altura significativamente superior a observada nos demais tratamentos. (Tabela 1).

$\mathrm{Na}$ emissão de folhas, as cultivares apresentaram comportamento diferenciado no solo sem cobertura e no solo coberto com aveia em pé, com maior número de folhas nas alfaces americana e crespa, respectivamente, de forma similar ao ocorrido na avaliação anterior (Tabela 2). Entretanto, o maior número de folhas da alface americana no solo sem cobertura não expressa necessariamente o adequado desenvolvimento das plantas, já que nessa condição a alface americana apresentou a menor massa fresca (Tabela 3). Possivelmente, contato das folhas inferiores da alface americana com 
MÓGOR, A.F. e CÂMARA, F.L.A. Produção de alface no sistema...

- solo no tratamento sem cobertura, e sua conseqüente senescência, devem ter promovido um efeito de estresse sobre as plantas, que entre suas conseqüências pode alterar o padrão de repartição de fotoassimilados (DAEI, 1996), modificar o balanço hormonal e a diferenciação celular (SAURE, 2001) e afetar a emissão de folhas (ANDRIOLO et al., 2003).

A diferença da massa fresca entre as plantas aos 24 DAT indica o efeito das coberturas do solo e interações com as cultivares (Tabela 3 ). O solo coberto com plástico preto promoveu o maior acúmulo de massa fresca e o solo sem cobertura o menor, enquanto manejos da palha promoveram acúmulo intermediário.

Com exceção da alface americana no solo coberto com plástico preto, o acúmulo de massa fresca não encontrou correspondência no teor de $\mathrm{N}$ das plantas (Tabela 4), pois apesar de diferenças significativas da massa fresca entre cultivares e manejos, os teores de $\mathrm{N}$ permaneceram adequados ao desenvolvimento das plantas.

Conforme descrito na metodologia, não houve adição de $\mathrm{N}$ ao solo, a não ser aquele contido na matéria orgânica (não quantificado), pela utilização de esterco bovino curtido na instalação do experimento. Portanto, o $\mathrm{N}$ acumulado pelas plantas deve ter origem, principalmente na mineralização do esterco aplicado antes do plantio da aveia, e da matéria orgânica anteriormente existente no solo.

Quanto à mineralização de $\mathrm{N}$ a partir da parte aérea da aveia preta, WISNIEWSKI E HOLTZ (1997) verificaram que após a completa senescência das plantas, foram necessários 179 dias para a palhada perder $71 \%$ de seu peso, bem como $71 \%$ do carbono, $75 \%$ do nitrogênio e $85 \%$ fósforo nela contidos. Considerando que no experimento o ciclo da alface foi de 36 dias, e que o transplante ocorreu logo após a completa senescência da aveia, a possibilidade da palhada, via mineralização, exercer influência sobre o teor de $\mathrm{N}$ das plantas de alface fica reduzida.

$\mathrm{Na}$ colheita (36 DAT), o solo coberto com plástico preto promoveu a maior altura das plantas em relação aos demais tratamentos (Tabela 1) possivelmente como reflexo do maior teor de $\mathrm{N}$ aos 12 e 24 DAT (Tabela 4). No solo sem cobertura se constatou a menor altura das plantas em relação aos demais tratamentos (Tabela 1), confirmando a tendência observada aos 12 e 24 DAT.

SEDIYAMA et al. (2000), trabalhando com diversas cultivares de alface americana, lisa e crespa em cultivo hidropônico, verificaram que o número de folhas da americana variou entre 16,43 e 29,87 ; da lisa entre 30,66 e 39,33; e da crespa entre 17,65 e 25,70. Para PEDROSA et al. (2000), em cultivo convencional a alface americana apresentou número de folhas variando entre 18 e 21 , a lisa entre 36 e 38 e a crespa, entre 21 e 27 . Comparando o número de folhas das plantas aos 36 DAT (Tabela 2) com os obtidos pelos autores citados, encontra-se correspondência com o da alface americana, exceto no solo coberto com aveia em pé. A alface lisa, em todos os tratamentos, apresentou número de folhas abaixo dos referidos, o menor no solo sem cobertura com 9,30; e o maior no solo coberto com plástico preto, com 21,17 (Tabela 2).

Ainda em relação à alface lisa, no solo sem cobertura o número de folhas entre 24 e 36 DAT não se alterou, indicando a não emissão de folhas novas ou senescência das velhas. A alface crespa apresentou número médio de 17,15 folhas, próximo ao menor valor encontrado por SEDIYAMA et al. (2000) de 17,65 folhas, exceto no solo sem cobertura, com 9,82 folhas, o menor valor entre os tratamentos (Tabela 2).

Verificou-se ao final do experimento (36 DAT) que os teores de $\mathrm{N}$ das plantas decresceram (Tabela 4), sendo de $24,6 \mathrm{~g} \mathrm{~kg}^{-1}$ na alface lisa em solo coberto com plástico preto, com o maior teor, e de $20,1 \mathrm{~g} \mathrm{~kg}$

${ }^{-1}$ na alface americana em solo coberto com aveia em pé, com o menor teor, entretanto permanecendo adequados ao desenvolvimento das plantas de acordo com SILVA JR. e SOPRANO (1997) e ALVARENGA et al. (2000), que encontraram teores variando de 50,0 a $20,0 \mathrm{~g} \mathrm{~kg}^{-1}$. Nesse sentido, GARCIA et al. (1988) verificaram a redução no teor de $\mathrm{N}$ das plantas ao final do ciclo da alface, quando comparado ao teor no período de maior emissão e expansão das folhas, atribuindo o decréscimo à redução na demanda com a aproximação do final do ciclo, bem como ao efeito de diluição pela máxima expansão das folhas.

Utilizando a massa fresca das plantas para expressar a produção de biomassa da alface no final do ciclo, PRADO et al. (1998) obtiveram 177,09 g para alface crespa e SEDIYAMA et al. (2000), comparando os três tipos de alface em cultivo hidropônico, obtiveram a média de $299,8 \mathrm{~g}$ para alface americana , 224,6 g para lisa e $219,8 \mathrm{~g}$ para crespa; enquanto VERDIAL et al. (2001) obtiveram $491,0 \mathrm{~g}$ para alface americana em solo coberto com plástico preto em sistema convencional. Comparando os resultados obtidos pelos autores com a massa fresca das plantas no final do experimento (36 DAT), verifica-se que no solo coberto com plástico preto, a produção de biomassa das alfaces americana, lisa e crespa com médias de 403,05 g, 236,70 g e 256,87 $\mathrm{g}$, respectivamente, bem como a produção de 202,70 g para alface lisa, e $205,27 \mathrm{~g}$ para a crespa no solo coberto com aveia deitada, e de $174,35 \mathrm{~g}$ e $185,15 \mathrm{~g}$ da alface crespa, nos solos cobertos com aveia ceifada e aveia em pé (Tabela 3), permaneceram próximas às encontradas nos diversos trabalhos, conduzidos em sistema convencional e hidropônico.

\section{CONCLUSÕES}

1. As coberturas do solo promoveram melhor desenvolvimento e maior produção de alface, quando comparadas ao solo sem cobertura.

2. Entre os manejos da cobertura do solo, o solo coberto com plástico preto promoveu a maior produção de alface.

3. Entre os manejos da palha, a alface lisa apresentou maior produção no solo coberto com aveia deitada, a crespa nos solos cobertos com aveia deitada e aveia em pé, e a americana nos solos cobertos com aveia ceifada e aveia em pé. 


\section{REFERÊNCIAS}

1. ALVARENGA, M.A.R.; SILVA da, E.C.; SOUZA de, R.J.; CARVALHO de, J.G. Crescimento, teor e acúmulo de macronutrientes em alface americana sob doses de nitrogênio aplicados no solo e níveis de cálcio aplicados via foliar. Horticultura Brasileira, v. 18 (suplemento), p. 803-804, 2000.

2. ANDRADE JÚNIOR, V.C.; YURI, J.E.; NUNES, U.R.; PIMENTA, F.L.; MATOS, C.S.M.; FLORIO, F.C.A.; MADEIRA, D.M. Emprego de tipos de cobertura de canteiro no cultivo da alface. Horticultura Brasileira, v. 23, n. 4, p. 899- 903, 2005.

3. ANDRIOLO, J.L.; ESPINDOLA, M.C.G.; STEFANELLO, M.O. Crescimento e desenvolvimento de plantas de alface provenientes de mudas com diferentes idades fisiológicas. Ciência Rural, v. 33, n. 1, p. 35-40, 2003.

4. BERTALOT, M.J.A.; MENDOZA, E.; GUERRINI, I.A. Growth parameters and nutrient content in four multipurpose tree species with potential characteristics for agroforestry systems in a cerrado region in Botucatu, São Paulo State, Brazil.. Journal of Sustainable Forestry, v. 15, n. 2, p. 87-105, 2002.

5. BORKERT,C.M.; GAUDÊNCIO, C.A.; PEREIRA, J.E.; PEREIRA, L.R.; OLIVEIRA JUNIOR, A. Nutrientes minerais na biomassa da parte aérea em culturas de cobertura de solo. Pesquisa Agropecuária Brasileira, v. 38, n. 1, p. 143-153, 2003.

6. CARDOSO, A.I.I. A cultura da abobrinha de moita. In: GOTO, R.; TIVELLI, S.W. (Org.). Produção de hortaliças em ambiente protegido: condições subtropicais. São Paulo: Fundação Editora da UNESP, 1998. p. 105-137.

7. CARVALHO, J.E.; ZANELLA, F.; MOTA, J.H.; LIMA, A.L.S. Cobertura morta do solo no cultivo de alface Cv. Regina 2000, em Ji-Paraná/RO. Ciência e Agrotecnologia, v. 29, n. 5, p. 935-939, 2005.

8. DAEI, J. Metabolic adjustements, assimilate partitioning, and alterations in source-sink relations in drought-stressed plants. In: ZAMSKY, E., SCHAFFER, A.A. Photoassimilate distribution in plants and crops. New York: Marcel Dekker, 1996. Cap. 17. p. 407-420.

9. FNP CONSULTORIA \& AGROINFORMATIVOS. Anuário Estatístico da Agricultura Brasileira. São Paulo: FNP, 2003. p. 190-192.

10. INSTITUTO BIODINÂMICO. Diretrizes. Botucatu: IBD, 2000. 54 p.

11. INSTITUTO BIODINÂMICO. Diretrizes. Botucatu: IBD, 2004. $87 \mathrm{p}$.

12. LYRA, G.B.; ZOLNIER, S.; COSTA, L.C.; SEDIYAMA, G.C.; SEDIYAMA, M.A.N. Modelos de crescimento para alface (Lactuca sativa L.) cultivada em sistema hidropônico sob condições de casa de vegetação. Revista Brasileira de Agrometeorologia, v. 11, n. 1, p. 69-77, 2003.

13. MALAVOLTA, E.; VITTI, G.C.; de OLIVEIRA, S.A. Avaliação do estado nutricional das plantas, princípios e aplicações. 2. ed. Piracicaba: Associação Brasileira para Pesquisa da Potassa e do Fosfato, 1997. 319 p.

14. MÜLLER, A.G. Comportamento térmico do solo e do ar em alface para diferentes tipos de cobertura do solo. Piracicaba, 1991. 77 f. Dissertação (Mestrado) - Escola Superior de Agricultura "Luiz de Queiroz", Universidade de São Paulo.

15. PEDROSA, M.W.; SEDIYAMA, M.A.N.; GARCIA, N.C.P.; SALGADO, L.T. Produção de alface em cultivo hidropônico em condições de inverno. Horticultura Brasileira, v. 18 (suplemento), p. 242-243, 2000.

16. PEREIRA, C.Z.; RODRIGUES, D.S.; GOTO, R. Efeito da cobertura do solo na produtividade da alface cultivada no verão. Horticultura Brasileira, v. 18 (suplemento), p. 492-493, 2000.

17. PRADO, A.R.A.; FREITAS, M.A.S.R.; SETÚBAL, J.W. Influência de diferentes tipos de cobertura morta em alface variedade Brisa XP-5552 no município de Terezina, P.I. In: SEMINÁRIO DE PESQUISAAGROPECUÁRIA DO PIAUÍ, 8, Terezina. Anais. Terezina: EMBRAPA-CNPMA, 1998. v. 1. p. 211-213.

18. SADE, A. Cultivo bajo condiciones forzadas: nociones generales. Israel: Estudio Rehak, 1998. $144 \mathrm{p}$.

19. SAURE, M.C. Blossom - end rot of tomato (Lycopersicon esculentum Mill) - a calcium - or a stress - related disorder. Scientia Horticulturae, v. 90, p. 193-208, 2001.

20. SEDIYAMA, M.A.N.; PEDROSA, M.W.; GARCIA, N.C.P.; GARCIA, S.R.L. Seleção de cultivares da alface para cultivo hidropônico. Horticultura Brasileira, v. 18 (suplemento), p. 244-45, 2000.

21. SILVA JÚNIOR, A.A.; SOPRANO, E. Caracterização de sintomas visuais de deficiências nutricionais em alface. Florianópolis: Epagri, 1997. 57 p.

20. TRANI, P.E.; PASSOS, F.A.; de AZEVEDO FILHO, J.A. Recomendações de adubação e calagem para o Estado de São Paulo. Campinas: Instituto Agronômico, 1996. p. 168-169. (IAC. Boletim, 100).

22. VERDIAL, M.F; LIMA, M.S.; MOGOR, A.F.; GOTO, R. Comportamento de alface tipo americana sob diferentes coberturas de solo. Horticultura Brasileira, v. 18 (suplemento), p. 486-88, 2000.

21. VERDIAL, M.F.; LIMA, M.S.; MOGOR, A.F.; GOTO, R. Production of iceberg lettuce using mulches. Scientia Agricola, v. 58, n. 4, p. 737-740, 2001.

22. WISNIEWSKI, C.; HOLTZ, G.P. Decomposição da palhada e liberação de nitrogênio e fósforo numa rotação aveia-soja sob plantio direto. Pesquisa Agropecuária Brasileira, v. 32, n. 11, p. 1035-1039, 1997. 
